\title{
Association between glycosylated hemoglobin A1C and bone biochemical markers in type 2 diabetic postmenopausal women: a cross-sectional study
}

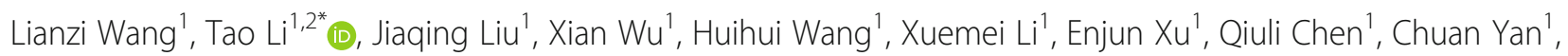
Huimin $\mathrm{Li}^{1}$, Yuanhong $\mathrm{Xu}^{1}$ and Wei Wei ${ }^{2^{*}}$

\begin{abstract}
Background: type 2 diabetes mellitus (T2DM) is a complicated disease that can affect bone health, but the change in bone biochemical markers caused by T2DM was controversial, so the aim of this study was to investigate whether there was a discrepancy in the levels of bone biochemical markers between postmenopausal women with T2DM and non-diabetic women and to explore the relationship between the level of glycosylated hemoglobin A1c (HbA1c) and bone biochemical markers in these subjects.

Methods: A total of 237 type 2 diabetic postmenopausal women visiting the First Affiliated Hospital of Anhui Medical University from January 2017 to October 2018 and 93 healthy postmenopausal women were retrospectively enrolled. The differences in the levels of bone biochemical markers between patients and controls were analyzed by one-way ANOVA or chi-square test. The relationship between $\mathrm{HbA} 1 \mathrm{c}$ and bone biochemical markers was analyzed by multivariate regression, forest plot and fitted curve.

Results: Bone formation markers including N-MID osteocalcin and procollagen type 1 amino-terminal pro-peptide (PINP) were decreased in postmenopausal women with T2DM compared to controls ( $17.42 \pm 9.50$ vs $23.67 \pm 7.58, p$ $<0.001 ; 48.47 \pm 27.27$ vs $65.86 \pm 21.06, p<0.001$, respectively), but the bone resorption markers $\beta$-crossLaps $(\beta-C T X)$ was no difference between the two groups $(0.57 \pm 0.28$ vs $0.55 \pm 0.21, p=0.868)$. Multivariate regression showed that HbA1c was inversely associated with N-MID osteocalcin and PINP after adjusting for age, BMl, menopause's years, diabetic duration, TC, TG, HDL-C, LDL-c, creatinine, UA and eGFR. The adjusted coefficients for N-MID osteocalcin and PINP per $1 \% \mathrm{HbA} 1 \mathrm{c}$ decrease were $-0.71(-1.19,-0.22)$ and $-1.79(-3.30,-0.28)$, respectively. A segmentation effect was seen in the fitted curve between $\mathrm{HbA1c}$ and $\beta$-CTX with an inflection point at $7.4 \%$ of $\mathrm{HbA} 1 \mathrm{c}$, the highest quartile of $\beta-\mathrm{CTX}(>=0.74 \mathrm{ng} / \mathrm{ml})$ showed a significantly negative with $\mathrm{HbA} 1 \mathrm{c}$. No significant association was seen between $\mathrm{HbA1c}$ and other biochemical markers.
\end{abstract}

Conclusions: Our study found that bone formation was inhibited in postmenopausal women with T2DM, but bone resorption was not affected, and poor glycemic control was related to lower levels of bone formation, may increase the risk of bone fracture in postmenopausal women with T2DM.

Keywords: HbA1c, N-MID osteocalcin, PINP, PTH, $\beta-C T X, 25(o h) D_{3}$

\footnotetext{
*Correspondence: limedical1974@126.com; wwei@ahmu.edu.cn

'Department of Clinical Laboratory, The First Affiliated Hospital of Anhui Medical University, No. 218 Jixi Road, Hefei 230032, Anhui, China

${ }^{2}$ Institute of Clinical Pharmacology, Anhui Medical University, Key Laboratory

of Anti-inflammatory and Immune Medicine, Ministry of Education, Anhui

Collaborative Innovation Center of Anti-inflammatory and Immune Medicine,

Anhui Anti-inflammatory and Immune Medicine innovation team, Hefei

230032, China
}

(c) The Author(s). 2019 Open Access This article is distributed under the terms of the Creative Commons Attribution 4.0 International License (http://creativecommons.org/licenses/by/4.0/), which permits unrestricted use, distribution, and reproduction in any medium, provided you give appropriate credit to the original author(s) and the source, provide a link to the Creative Commons license, and indicate if changes were made. The Creative Commons Public Domain Dedication waiver (http://creativecommons.org/publicdomain/zero/1.0/) applies to the data made available in this article, unless otherwise stated. 


\section{Background}

Type 2 diabetes mellitus (T2DM), a complex multifactorial disease affecting sugar, fat and protein metabolism, has consistently been a global health problem with negative effects on mortality. It can also lead to a dysregulation in the handling of calcium, phosphorus and magnesium, thus leading to a series of complications such as cardiovascular disease, peripheral vascular disease, retinal disease, and neuropathy. Bone is also affected by T2DM. Osteoporosis is a long-term complication of T2DM that is prevalent in postmenopausal women, and previous studies have shown that risk of fractures was significantly higher in patients with T2DM than in those without T2DM; therefore, researchers have focused on the effect of diabetes on bone mineral density (BMD). BMD has been shown to be decreased or normal in T2DM patients in some studies [1-4], while other studies have reported that T2DM is associated with higher BMD [5]. Recently, increasingly more attention has been paid to the differences in bone metabolism in patients with diabetes mellitus. Bone biochemical markers reflect the bone turnover process and hence mirror bone resorption and formation processes [6]. Changes in bone turnover can be assessed by measuring serum levels of $\beta$-CTX, PINP, parathyroid hormone (PTH), N-MID osteocalcin and 25-hydroxyvitamin $\mathrm{D}_{3}\left(25(\mathrm{OH}) \mathrm{D}_{3}\right)$, which have the advantage of reflecting alterations in bone formation and resorption.

However, studies on bone biochemical markers in T2DM have shown conflicting results, with the inhibition of bone formation being reported in most cases [7-9]; a recent survey indicated that there was no difference in bone turnover between Iranian postmenopausal women with and those without diabetes [10]. HbA1c is a stable marker that can characterizes dysglycemia more efficiently than fasting glucose in terms of long-term glucose regulation, Puar $\mathrm{TH}$ et al. noted that tight glycemic control (when HbA1c $<7 \%$ ) was closely related with a greater risk of hip fracture in individuals being treated for T2DM [11]; in contrary, Schwartz et al. found no increase in the fall risk of patients with standard glydemic control [12]. However, little research has focused on the association between the level of HbA1c and bone biochemical markers. And given the large heterogeneity of these studies, we conducted these experiments to identify the differences between T2DM patients and controls and formulated the following hypothesis: glycosylated hemoglobin A1c levels affect the level of bone biochemical markers.

\section{Subjects and methods}

\section{Subjects}

This was a cross-sectional study that included patients from the First Affiliated Hospital of Anhui Medical
University diagnosed with T2DM. Patients with the following diseases that influenced the bone metabolism ware excluded: hyperparathyroidism, hypercortisolism, osteoporosis, chronic liver disease, malignant tumor, Cushing's syndrome, acromegaly, rheumatoid arthritis, thyroid disease, ankylosing spondylitis, chronic obstructive pulmonary disease and chronic kidney disease including diabetic nephropathy. Patients who had a history of taking estrogen, parathyroid hormone, glucocorticoids (more than 3 months), anti-seizure drugs, bisphosphonates was also excluded. A group of 237 postmenopausal women were ultimately included in this study. The average age of the subjects was $64.41 \pm 9.23$ years. Recruitment occurred from January 2017 to October 2018, in additional, postmenopausal women visited the hospital only for a health examination matched for age to T2DM with normal glucose tolerance from healthy examination center of the First Affiliated Hospital of Anhui Medical University were enrolled in our survey, according to the medical examination report, 93 controls meet our standard in the end, average age of the controls was $64.61 \pm$ 7.62 years. T2DM was defined according to the updated and approved diagnostic criteria for diabetes of the American Diabetes association (ADA) released in 2017, when fasting plasma glucose was (FPG) $\geq 7.0 \mathrm{mmol} / \mathrm{L}$ and/ or 2 -h posted-glucose (PG) was $\geq 200 \mathrm{mg} / \mathrm{dL}(11.1 \mathrm{mmol} /$ L) during oral glucose tolerance test (OGTT) and/or HbA1c $\geq 6.5 \%$; normal glucose tolerance was a status that fasting plasma glucose was (FPG) $<6.1 \mathrm{mmol} / \mathrm{L}$ and/or 2 -h posted-glucose $(\mathrm{PG})$ was $<7.8 \mathrm{mmol} / \mathrm{L}$ ) during oral glucose tolerance test (OGTT). This research was approved by the Ethics Review Committee of the First Affiliated Hospital of Anhui Medical University (Reference number Quick-PJ2018-11-11).

\section{Biochemical measurements \\ Blood specimen collection}

Blood samples were collected after fasting for at least 8 h. The samples were then centrifuged for $5 \mathrm{~min}$ at 3500 $\mathrm{r} / \mathrm{s}$ within $2 \mathrm{~h}$. The serum was then stored at $-20^{\circ} \mathrm{C}$ and was subsequently used to measure the levels of bone biochemical markers, including $\beta$-CTX, PINP, PTH, $\mathrm{N}$-MID osteocalcin and $25(\mathrm{OH}) \mathrm{D}_{3}$ and other variables, including total cholesterol (TC), triglycerides (TG), high-density lipoprotein-cholesterol (HDL-c), low-density lipoprotein-cholesterol (LDL-c), creatinine, uric acid (UA) and estimated glomerular filtration rate (eGFR).

\section{Methods}

The bone markers PTH, PINP, $\beta$-CTX, N-MID osteocalcin and $25(\mathrm{OH}) \mathrm{D}_{3}$ were measured using electrochemiluminescence immunoassay (Cobas 601, Roche Diagnostics), and glycosylated hemoglobin A1c (HbA1c) was measured by high-performance liquid chromatography (HPLC) using 
Bio-Rad D-10. Serum TC, TG, HDL-c, and LDL-c were detected by immunoturbidimetry. The within and between batch coefficients of variation were both $<8 \%$. The laboratory was certified by ISO 15189.

The weight of the patients was measured with a calibrated balance-beam scale and height was measured using a stadiometer. Body Mass Index (BMI) was calculated using the formula weight divided by the square of height $\left(\mathrm{kg} / \mathrm{m}^{2}\right)$. The information containing patient's age, BMI, menopauses years, duration of T2DM, diabetic complications including microvascular complications(diabetic peripheral neuropathy (DPN) and diabetic retinopathy (DR)) and macrovascular complications (including atherosclerosis, hypertension), history of fracture, use of stain medication, and treatment type of hyperglycemia were collected.

\section{Statistical analysis}

All continuous variables were expressed as the mean \pm standard deviation(SD) or median (interquartile range), while categorical variables were described as a frequency or percentage. One-way ANOVA was used to compare continuous variables, and a chi-square test was used for categorical variables. Multiple regression analysis was used to estimate the independent association between $\mathrm{HbA1c}$ and bone biochemical markers while adjusting for potential confounders. Stratified and interaction analyses were implemented according to age $(<60$ or $\geq 60$ years), menopause years $(<10$ or $\geq 10$ years), BMI $(<24$ or $\left.\geq 24 \mathrm{~kg} / \mathrm{m}^{2}\right)$, diabetic duration ( $<10$ or $\geq 10$ years), history of fracture (yes or no), microvascular complications (yes or no), macrovascular complications (yes or no), and treatment type (insulin, anti-diabetic drugs or combination therapy), use of stain medication(yes or no), the results were presented through forest plot. Spline smoothing of the generalized additive models was performed to explore the relationship between $\mathrm{HbA1c}$ and these outcomes.

All of the analyses were performed using the software $R$ for statistical computing (http://www.R-project.org, The R Foundation) and the software Stata (version 14.1, Stata Corp). $P<0.05$ was considered statistically significant.

\section{Results}

\section{Comparison of bone biochemical markers between} postmenopausal women with T2DM and the controls Bone metabolism markers in T2DM patients and controls are shown in Table 1. Bone formation markers N-MID osteocalcin and PINP were significantly lower in postmenopausal women with T2DM than in the controls. Similarly, there was an obvious reduction in PTH and $25(\mathrm{OH}) \mathrm{D}_{3}$ in $\mathrm{T} 2 \mathrm{DM}$ patients compared to controls. However, we were unable to find a significant difference in the bone resorption marker $\beta$-CTX between the diabetic group and the control group, the levels of blood lipids were also significantly different between the two groups.

\section{General characteristics of postmenopausal patients with T2DM}

A total of 214 postmenopausal patients with T2DM were enrolled in this research. The clinical information of the recruited patients was listed in Table 2 . The mean age was $64.41 \pm 9.23$ years, mean menopause's years was $13.77 \pm 9.55$ years, mean diabetic duration was $12.08 \pm$ 8.64 years, and mean BMI was $12.08 \pm 8.64(\mathrm{~kg} / \mathrm{m} 2)$. Only 17 patients had a history of fracture; 183 patients were accompany with microvascular complications; 144 patients were suffered with macrovascular complications; 63 of 214 patients received insulin treatment only, 23 patients used anti-diabetic drugs only, 151 patients were using combination therapy(Table 2). The patients were divided into two groups according to the level of their serum HbA1c level (greater or less than 8.5\%)(Table 3). A higher level of serum N-MID osteocalcin and PTH was observed in the HbA1c $<8.5$ group $(p<0.05)$, but no significant difference in the level of serum PINP, $\beta$-CTX and $25(\mathrm{OH}) \mathrm{D}_{3}$ was observed. History of fracture, microvascular or macrovascula rcomplications and treatment strategy also had no difference between the HbAlc $<8.5 \%$ group and the HbAlc $>8.5 \%$ group, however, the use of statin medication was different obviously, moreover, individuals with higher $\mathrm{HbA1c}$ level were likely to have a higher levels of eGFR and TG but a lower levels of creatinine and HDL-c.

\section{Association between $\mathrm{HbA} 1 \mathrm{c}$ and the bone biochemical markers in postmenopausal women with T2DM}

To investigate whether the bone biochemical markers levels in T2DM are associated with $\mathrm{HbA1c}$, we performed a multivariate regression analysis after adjusting for different variables (Table 3). Linear relationships were observed between HbA1c and N-MID osteocalcin or PINP in all of the five adjusted models. In the unadjusted model (model 1), HbA1c increments were negatively correlated with N-MID osteocalcin and PINP, and each $1 \%$ HbA1c increment was associated with a lower level of N-MID osteocalcin with a $\beta(95 \% \mathrm{CI})$ of $0.92(-1.42,-0.41)$, and a lower level of PINP with a $\beta$ $(95 \% \mathrm{CI})$ of $-1.98(-3.44,-0.52)$, however, after adjusting for potential confounders (model 2, model 3, model 4 and model 5), the association between HbAlc and N-MID osteocalcin was attenuated but still present, the trend in the relationship between HbA1c and PINP was also weakened, the negative relationships between $\mathrm{HbAlc}$ vs N-MID osteocalcin and HbAlc vs PINP among model2, 3, 4 and 5 had little change. Nevertheless, we did 
Table 1 General characteristics of the T2DM and controls

\begin{tabular}{|c|c|c|c|}
\hline & $\begin{array}{l}\text { T2DM } \\
(n=237)\end{array}$ & $\begin{array}{l}\text { Control } \\
(n=93)\end{array}$ & $P$ value \\
\hline age(years) & $64.41 \pm 9.23$ & $64.61 \pm 7.62$ & 0.900 \\
\hline $\begin{array}{l}\text { Menopause's } \\
\text { years(years) }\end{array}$ & $13.77 \pm 9.55$ & $14.13 \pm 13.21$ & 0.783 \\
\hline $\begin{array}{l}\text { Diabetic } \\
\text { duration(years) }\end{array}$ & $12.08 \pm 8.64$ & None & NA \\
\hline $\begin{array}{l}\text { Fasting } \\
\text { glucose(mmol/L) }\end{array}$ & NA & $5.32 \pm 0.60$ & NA \\
\hline $\mathrm{HbA1c}$ & $9.36 \pm 2.35$ & $5.67 \pm 0.33$ & $<0.001$ \\
\hline PINP(ng/ml) & $48.47 \pm 27.27$ & $65.86 \pm 21.06$ & $<0.001$ \\
\hline PTH(pg/ml) & $43.43 \pm 30.05$ & $50.34 \pm 20.85$ & $<0.001$ \\
\hline $\begin{array}{l}\text { N-MID } \\
\text { osteocalcin(ng/ml) }\end{array}$ & $17.42 \pm 9.50$ & $23.67 \pm 7.58$ & $<0.001$ \\
\hline$\beta-C T X(n g / m l)$ & $0.57 \pm 0.28$ & $0.55 \pm 0.21$ & 0.868 \\
\hline $25(\mathrm{OH}) \mathrm{D}_{3}(\mathrm{ng} / \mathrm{ml})$ & $11.22 \pm 6.83$ & $18.39 \pm 5.62$ & $<0.001$ \\
\hline $\mathrm{TC}(\mathrm{mmol} / \mathrm{L})$ & $4.54(3.79-5.31)$ & $5.25(4.60,6.02)$ & $<0.001$ \\
\hline $\mathrm{TG}(\mathrm{mmol} / \mathrm{L})$ & $1.45(1.03-2.17)$ & $1.21(0.95,1.67)$ & 0.002 \\
\hline $\mathrm{HDL}-\mathrm{c}(\mathrm{mmol} / \mathrm{L})$ & $1.16(0.96-1.41)$ & $1.58(1.34,1.82)$ & $<0.001$ \\
\hline $\mathrm{LDL}-\mathrm{c}(\mathrm{mmol} / \mathrm{L})$ & $2.67(1.99-3.30)$ & $3.23(2.46,3.85)$ & $<0.001$ \\
\hline $\begin{array}{l}\text { History of fracture, } \\
\mathrm{n}(\%)\end{array}$ & $17(7.17 \%)$ & None & NA \\
\hline $\begin{array}{l}\text { Microvascular } \\
\text { complications, n (\%) }\end{array}$ & $183(77.22 \%)$ & None & NA \\
\hline $\begin{array}{l}\text { Macrovascular } \\
\text { complications, n (\%) }\end{array}$ & $144(60.76 \%)$ & None & NA \\
\hline Treatment & & None & NA \\
\hline Insulin, n(\%) & 63 (26.58\%) & None & NA \\
\hline $\begin{array}{l}\text { Oral anti-diabetic } \\
\text { agents, } \mathrm{n}(\%)\end{array}$ & $23(9.70 \%)$ & None & NA \\
\hline $\begin{array}{l}\text { Insulin+Oral } \\
\text { anti-diabetic agents, } \\
\text { n (\%) }\end{array}$ & $151(63.71 \%)$ & None & NA \\
\hline $\begin{array}{l}\text { Use of statin } \\
\text { medication }\end{array}$ & 112 (47.26\%) & None & NA \\
\hline
\end{tabular}

Data were presented as number (percentage) for categorical data, (mean \pm standard deviation) for parametrically distributed data or median (interquartile range) for nonparametrically distributed data. NA: not available

not find a linear association between $\mathrm{HbA} 1 \mathrm{c}$ and the other biochemical markers studied.

Stratified and interaction analyses according to age ( $<60$ or $\geq 60$ years), menopauses years ( $<10$ or $\geq 10$ years), and BMI $\left(<24\right.$ or $\left.\geq 24 \mathrm{~kg} / \mathrm{m}^{2}\right)$ diabetic duration $(<10$ or $\geq$ 10 years), history of fracture(yes or no), microvascular complications (yes or no), macrovascular complications (yes or no), treatment type (insulin, anti-diabetic drugs or combination therapy) and use of stain medication(yes or no) are shown in the forest plot (Fig. 1 and Fig. 2), In patients with a history of fracture, HbA1c was negatively correlated with N-MID osteocalcin with a $\beta(95 \% \mathrm{CI})$ of $2.34(-5.70,1.03)$, while a $\beta(95 \% \mathrm{CI})$ of $-0.62(-1.09$, $0.14)$, in the patients without a history of fracture,
Table 2 General characteristics of the T2DM in postmenopausal women according to $\mathrm{HbA} 1 \mathrm{c}$ more or lower than $8.5 \%$

\begin{tabular}{|c|c|c|c|}
\hline & $\begin{array}{l}\mathrm{HbA} 1 \mathrm{c} \\
<8.5 \%\end{array}$ & $\begin{array}{l}\mathrm{HbA} 1 \mathrm{c} \\
\geq 8.5 \%\end{array}$ & $P$ value \\
\hline $\mathrm{N}$ & 103 & 134 & \\
\hline Age(years) & $65.38 \pm 9.36$ & $63.67 \pm 9.09$ & 0.158 \\
\hline $\begin{array}{l}\text { Menopause's } \\
\text { years(years) }\end{array}$ & $14.32 \pm 9.37$ & $13.34 \pm 9.71$ & 0.436 \\
\hline Diabetic duration(years) & $12.44 \pm 8.20$ & $11.81 \pm 8.98$ & 0.583 \\
\hline $\mathrm{BMI}\left(\mathrm{Kg} / \mathrm{m}^{2}\right)$ & $24.54 \pm 3.74$ & $24.21 \pm 4.16$ & 0.525 \\
\hline $\mathrm{eGFR}\left(\mathrm{mL} / \mathrm{min} / 1.73 \mathrm{~m}^{2}\right)$ & $81.43 \pm 24.98$ & $92.40 \pm 21.45$ & 0.001 \\
\hline creatinine $(\mu \mathrm{mol} / \mathrm{L})$ & $77.21 \pm 43.50$ & $63.02 \pm 22.33$ & 0.001 \\
\hline $\mathrm{UA}(\mathrm{mg} / \mathrm{dL})$ & $301.52 \pm 96.58$ & $278.51 \pm 103.94$ & 0.083 \\
\hline $\mathrm{TC}(\mathrm{mmol} / \mathrm{L})$ & $4.52(3.84-5.16)$ & $4.55(3.76-5.41)$ & 0.666 \\
\hline $\mathrm{TG}(\mathrm{mmol} / \mathrm{L})$ & $1.36(1.02-1.82)$ & $1.65(1.10-2.42)$ & 0.013 \\
\hline $\mathrm{HDL}-\mathrm{c}(\mathrm{mmol} / \mathrm{L})$ & $1.22(1.05-1.47)$ & $1.11(0.92-1.33)$ & 0.007 \\
\hline $\mathrm{LDL}-\mathrm{c}(\mathrm{mmol} / \mathrm{L})$ & $2.68(2.04-3.19)$ & $2.63(1.98-3.42)$ & 0.792 \\
\hline N-MID osteocalcin(ng/ml) & $19.84 \pm 10.71$ & $15.56 \pm 8.01$ & $<0.001$ \\
\hline PINP(ng/ml) & $51.71 \pm 29.88$ & $45.97 \pm 24.90$ & 0.153 \\
\hline$\beta-C T X(n g / m l)$ & $0.61 \pm 0.31$ & $0.53 \pm 0.26$ & 0.062 \\
\hline PTH(pg/ml) & $49.09 \pm 37.89$ & $39.08 \pm 21.38$ & 0.021 \\
\hline $25(\mathrm{OH}) \mathrm{D}_{3}(\mathrm{ng} / \mathrm{ml})$ & $10.94 \pm 6.92$ & $11.44 \pm 6.78$ & 0.492 \\
\hline History of fracture,n (\%) & $6(5.83 \%)$ & $11(8.21 \%)$ & 0.614 \\
\hline $\begin{array}{l}\text { Microvascular } \\
\text { complications, n (\%) }\end{array}$ & $78(75.73 \%)$ & $105(78.36 \%)$ & 0.632 \\
\hline Dyascular & $63(61.17 \%)$ & 81 (60.45\%) & 0.9 \\
\hline
\end{tabular}

complications, n (\%)

\begin{tabular}{llll} 
& \multicolumn{1}{c}{ Treatment } & & \\
Insulin,n(\%) & $27(26.21 \%)$ & $36(26.87 \%)$ & 0.901 \\
$\begin{array}{l}\text { Oral anti-diabetic } \\
\text { agents,n(\%) }\end{array}$ & $9(8.74 \%)$ & $14(10.45 \%)$ & \\
$\begin{array}{l}\text { Insulin+Oral anti-diabetic } \\
\text { agents, n(\%) }\end{array}$ & $67(65.05 \%)$ & $84(62.69 \%)$ & \\
$\begin{array}{l}\text { Use of statin } \\
\text { medication }\end{array}$ & $37(35.92 \%)$ & $75(55.97 \%)$ & 0.002 \\
\hline
\end{tabular}

Data were presented as number (percentage) for categorical data, (mean \pm standard deviation) for parametrically distributed data or median (interquartile range) for nonparametrically distributed data

influence of HbA1c on bone biochemical markers in the two group was different significantly (interaction $p$ value $=0.033$ )

As for the linear relationship between $\mathrm{HbA} 1 \mathrm{c}$ and N-MID osteocalcin, and between HbA1c and PINP, we speculated that a nonlinear relationship existed between HbA1c and the other biochemical markers studied. We used smoothing splines generated in the generalized additive models to explore $\mathrm{HbA1c}$ and these outcomes (Fig. 3). A linear relationship was found between HbA1c and N-MID osteocalcin and between HbA1c and PINP with a statistically significant, which was consistent with 
Table 3 Association between the level of HbA1c with bone biochemical markers in T2DM of postmenopausal women

\begin{tabular}{clllll}
\hline & N-MID osteocalcin & PINP & $\beta-C T X$ & $P T H$ & \\
& $\beta(95 \% \mathrm{Cl})$ & $\beta(95 \% \mathrm{Cl})$ & $\beta(95 \% \mathrm{Cl})$ & $\begin{array}{l}25(\mathrm{OH}) \mathrm{D}_{3} \\
\beta(95 \% \mathrm{Cl})\end{array}$ \\
\hline HbA1C & & & & & \\
Model1 & $-0.92(-1.42,-0.41)$ & $-1.98(-3.44,-0.52)$ & $-0.01(-0.03,0.00)$ & $-1.29(-2.91,0.34)$ & $0.05(-0.32,0.42)$ \\
Model2 & $-0.71(-1.19,-0.22)$ & $-1.79(-3.30,-0.28)$ & $-0.01(-0.03,0.00)$ & $-0.14(-1.49,1.21)$ & $-0.00(-0.39,0.39)$ \\
Model3 & $-0.71(-1.20,-0.22)$ & $-1.80(-3.30,-0.30)$ & $-0.01(-0.03,0.00)$ & $-0.14(-1.50,1.21)$ & $-0.00(-0.39,0.39)$ \\
Model4 & $-0.71(-1.20,-0.22)$ & $-1.85(-3.36,-0.34)$ & $-0.01(-0.03,0.01)$ & $-0.13(-1.49,1.24)$ & $-0.02(-0.41,0.37)$ \\
Model5 & $-0.70(-1.20,-0.20)$ & $-1.73(-3.27,-0.20)$ & $-0.01(-0.03,0.01)$ & $-0.10(-1.50,1.29)$ & $-0.10(-0.50,0.30)$ \\
\hline
\end{tabular}

Values were based on linear regression models and reflect the difference and 95\%Cl for HbA1c, Model1 was non-adjusted, Model 2 was adjusted for age, BMI, menopause's years, diabetic duration, TC, TG, HDL-C, LDL-C, creatinine, UA and eGFR. Model 3 was adjusted for variables in Model 2 and history of fracture (Yes or No). model 4 was adjusted for variables in Mode3, microvascular complications (Yes or No) and macrovascular complication (Yes or No). model 5 was adjusted for variables in Mode4, the treatment of T2DM (insulin, anti-diabetic agents or insulin+ anti-diabetic agents) and the use of statin medication(Yes or No)

the results of the multiple regression. Interestingly, a segmentation effect was observed between $\mathrm{HbA} 1 \mathrm{c}$ and $\beta$-CTX in our investigation. A negative association was identified between $\mathrm{HbA} 1 \mathrm{c}$ and $\beta$-CTX with a $\beta(95 \% \mathrm{CI})$ of $-0.11(-0.22,-0.01)$ when HbA1c was less than $7.4 \%$, but no significant relation was observed with $\beta$-CTX when HbA1c was greater than $7.4 \%$ (Table 4). To testify this interesting segmentation effect, we quartered the level of $\beta$-CTX, and a multiple linear regression analysis was performed, as shown in Table 5, a significant negative relationship was shown between HbA1c and the highest quartile of $\beta$-CTX ( $>=0.74 \mathrm{ng} /$ $\mathrm{ml}$ ), but no significant association with HbA1c when $\beta$-CTX was less than 0.74 , which was nearly accordance with the fitted curve.

\section{Discussion}

Clearly, glucose metabolism is closely related to bone metabolism, as bone biochemical markers in patients with diabetes were affected by many factors, such as the

\begin{tabular}{|c|c|c|c|c|}
\hline & & $\beta$ & $95 \% \mathrm{Cl}$ & interaction $\mathrm{p}$ value \\
\hline \multicolumn{4}{|l|}{ Age(years) } & \\
\hline$>=60$ & & -0.72 & $(-1.31,-0.13)$ & \multirow{2}{*}{0.8001} \\
\hline \multirow{2}{*}{\multicolumn{5}{|c|}{ Menopause's years(years) }} \\
\hline$\approx 10$ & & -0.69 & & \\
\hline$x=10$ & & -083 & $(-153-0.14)$ & 0.2357 \\
\hline \multicolumn{5}{|l|}{$\mathrm{BMI}(\mathrm{Kg} / \mathrm{m} 2)$} \\
\hline$\approx 24$ & & -0.45 & $(-0.94,0.04)$ & \multirow{2}{*}{0.1724} \\
\hline \multirow{2}{*}{\multicolumn{5}{|c|}{ Diabetic duration(years) }} \\
\hline & & & & \\
\hline$<10$ & & -0.38 & $(-1.28,0.52)$ & \multirow{2}{*}{0.9063} \\
\hline$>=10$ & & -0.76 & $(-1.36,-0.15)$ & \\
\hline \multicolumn{5}{|l|}{ History of fracture } \\
\hline No & & -0.62 & $(-1.09,-0.14)$ & \multirow[t]{2}{*}{0.0332} \\
\hline Yes & & -2.34 & $(-5.70,1.03)$ & \\
\hline \multicolumn{5}{|l|}{ Microvascular complication } \\
\hline No & & -0.23 & $(-1.13,0.67)$ & \multirow{3}{*}{0.1838} \\
\hline Yes & 4 & -0.82 & $(-1.40,-0.24)$ & \\
\hline \multicolumn{4}{|l|}{ Macrovascular complication } & \\
\hline No & & -0.6 & $(-1.19,-0.01)$ & \multirow[t]{2}{*}{0.2362} \\
\hline Yes & & -0.78 & $(-1.50,-0.05)$ & \\
\hline \multicolumn{5}{|l|}{ Treatment } \\
\hline insulin & $\mapsto$ & -0.75 & $(-1.66,0.16)$ & \multirow[t]{3}{*}{0.1481} \\
\hline antidiabetic drugs & & 0.69 & $(-2.53,3.91)$ & \\
\hline \multirow{2}{*}{\multicolumn{5}{|c|}{ use of statin medication }} \\
\hline & & & & \\
\hline Yes & 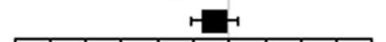 & -0.42 & $(-1.08,0.23)$ & \multirow{2}{*}{0.128} \\
\hline & $+0+2-1012=$ & & & \\
\hline \multicolumn{5}{|c|}{$\begin{array}{l}\text { Fig. } 1 \text { Associations of the N-MID osteocalcin with HbA1c in strata of age, menopause years, BMI, diabetic duration, history of fracture, } \\
\text { microvascular complication, macrovascular complication, treatment, use of statin medication, and the interaction between subgroup.Data was } \\
\text { adjusted for age, BMI, menopause's years, diabetic duration, TC, TG, HDL-c, LDL-c, creatinine, UA and eGFR }\end{array}$} \\
\hline
\end{tabular}




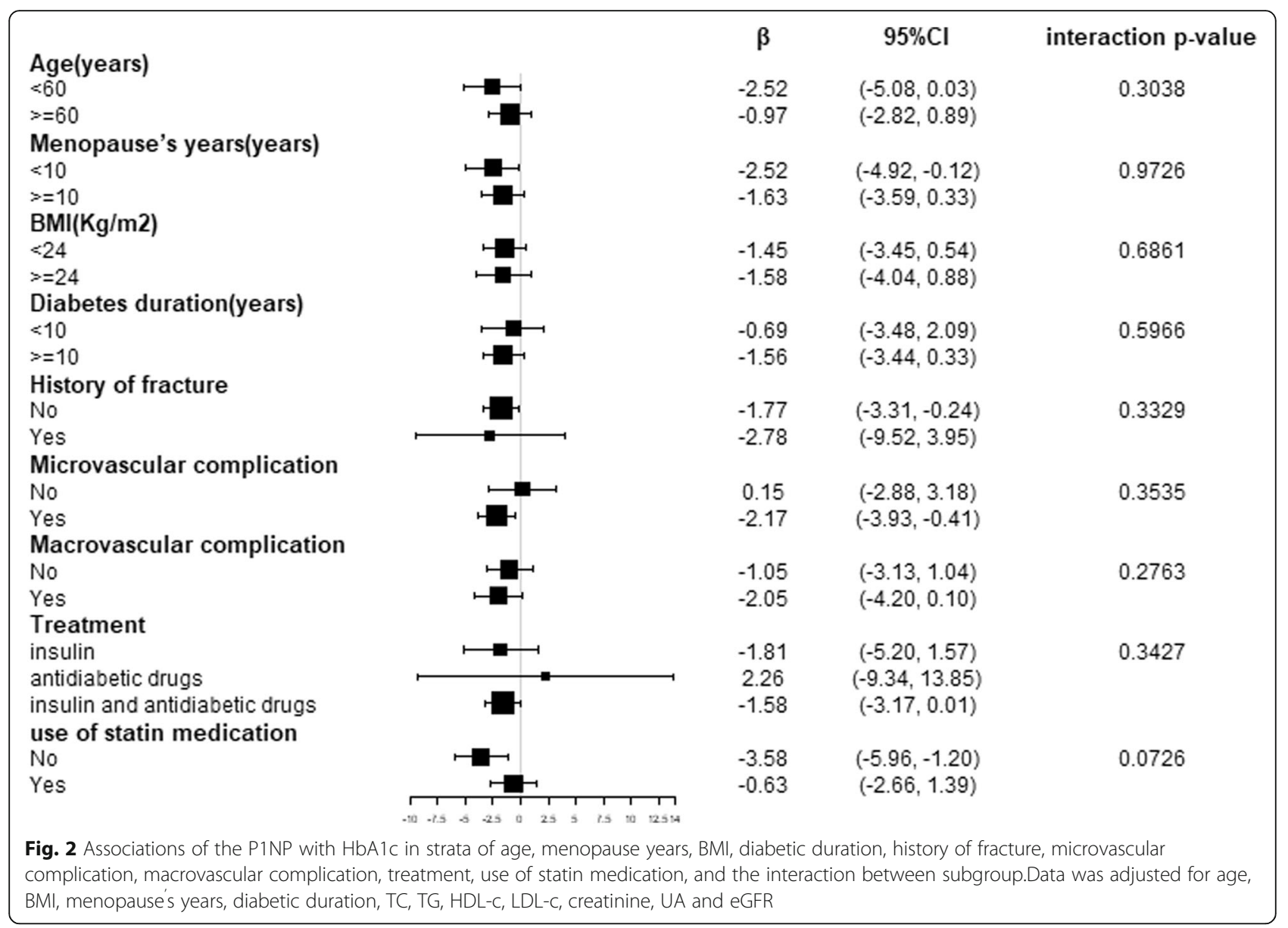
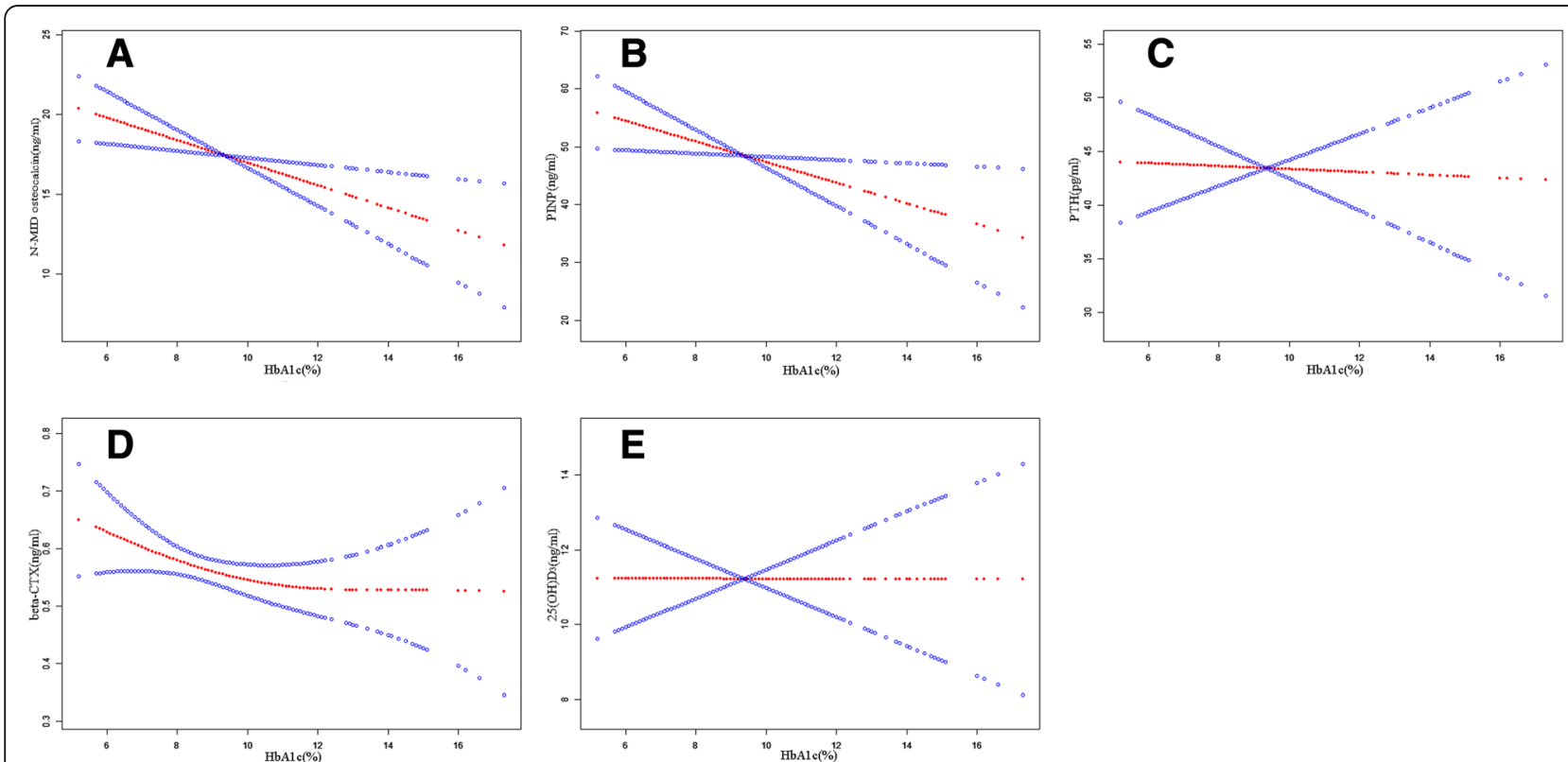

Fig. 3 Smoothing splines of $\mathrm{HbA1c}$ and bone biochemical markers generated in generalized additive models. General associations between HbAlc and N-MID osteocalcin (a), and PICP (b); PTH (c), and $\beta-C T X(\mathbf{d}) ; 25(\mathrm{OH}) \mathrm{D}_{3}(\mathbf{e})$. Adjusted for age, BMI, menopause's years, diabetic duration, TC, TG, HDL-C, LDL-c, creatinine, UA, and eGFR. The line of dark blue circles indicates $95 \%$ confidence intervals 
Table 4 Segmentation effect between HbA1c and $\beta-C T X$

\begin{tabular}{lll}
\hline & $\beta-C T X$ & \\
& $\beta(95 \% \mathrm{Cl})$ & $P$ value \\
\hline HbA1C & & \\
$<=7.4 \%$ & $-0.11(-0.22,-0.01)$ & 0.0325 \\
$>7.4$ & $-0.00(-0.02,0.02)$ & 0.8073 \\
\hline
\end{tabular}

Data was adjusted for age, BMl, menopause's years, diabetic duration, TC, TG, HDL-C, LDL-c, creatinine, UA and eGFR

type of diabetes, the presence of complications, history of fractures, the treatment type and so on. However, how T2DM affects bone metabolism in postmenopausal women remains unclear. Studies on bone turnover markers in type 2 diabetic patients have reported conflicting results, and a consensus has not yet been reached. In this investigation, we explored the association between bone turnover and type 2 diabetes in postmenopausal women.

In this research, we found that the bone formation markers N-MID osteocalcin and PINP were lower in postmenopausal women with T2DM than in the controls, in agreement with most studies [7-9]. The inhibition of bone formation in T2DM may be due to the accumulation of advanced glycation end-products in the organic bone matrix, which may interfere with normal osteoblast function [13]. Furthermore, hyperglycemia may have a direct influence on bone cells by increasing the expression of sclerostin in osteocytes to inhibit bone formation [14].

At the same time, the bone resorption marker $\beta$-CTX did not show any discrepancies between diabetic patients and controls in our investigation. $\beta$-CTX was a confusing and controversial biochemical marker in T2DM all the time. Consistently with our results, $\beta$-CTX had no differ in T2DM patients and non-diabetic patients in some studies $[15,16]$, other bone resorption indices including bone surface and osteoclast number had no difference between T2DM and controls [17], indicating a suppression of bone formation in T2DM but no alteration in bone resorption. Other studies have shown conflicting results-that there is a lower level of $\beta$-CTX in patients with T2DM $[18,19]$. However, we performed a univariate analysis only to analyze the discrepancy of bone markers between the two groups, thus, the results of studies was varied may be explained by differences in metabolic status, diabetic duration, and treatment type in patients with T2DM.
Among postmenopausal women with T2DM, we found N-MID osteocalcin and PINP was negatively correlated with $\mathrm{HbA1c}$ in type 2 diabetes with or without adjustment, indicating that a poor glycemic control may be associated with a reduction of bone formation. After adjusting for the variables we collected, the opposite relationship was weakened, interaction analyses in stratified subgroup showed age, menopause years, BMI, diabetic duration, history of fracture, microvascular complication, macrovascular complication and treatment of T2DM did not influenced the relation between HbA1c and PINP. However a stratification analysis according to history of fracture(Yes or No) conducted showing a significant difference of N-MID osteocalcin in the two subgroups based on HbAlc, which means HbA1c does not independently affect the level of N-MID osteocalcin, but is affected by a history of fractures. Some previous reports detected insulin treatment may not affected the bone biochemical markers, metformin treatments could decrease the bone biochemical markers [20, 21]; nevertheless, Dyah Purnamasari indicated insulin and metformin didnt alter bone metabolism [8]. A study showed low serum UA concentration may be associated with lower BMD values [22], a population-based study of 3028 older older women indicated statin use was related with lower cortical porosity [23], the effect of diabetic complications on bone metabolism remains unknown, so we need to adjust these confounds in our study, and further research should pay more attention to the effect of renal function, anti-diabetic agents and diabetic complication on bone metabolism.

In a type 1 diabetic mouse model, Botolin et al. [24] detected that the function of osteoblasts was inhibited by hyperglycemia. This effect of hyperglycemia may be similar in humans, and our results suggest a dysfunction in osteoblasts in diabetic patients. Targeted knock out of the osteocalcin gene (Ocn-l-) in mice resulted in the development of glucose intolerance and a decrease in the number of pancreatic beta cells, while OC favored $\beta$-cell proliferation, insulin secretion, and sensitivity through adiponectin [25]. The wnt/ $\beta$-catenin signaling pathway is also involved in glucose metabolism and affects the level of OC [26]. The association between the levels of HbA1c and its influence on OC through wnt/ $\beta$-catenin signaling needs to be explored further.

Table 5 Association of $\beta$-CTX quartile as ordinal variables with $\mathrm{HbA1C}$ in multivariate regression

\begin{tabular}{lllll}
\hline & $\beta-C T X$ & & Q3 & Q4 \\
\cline { 2 - 5 } & Q1 & Q2 & $0.01(-0.00,0.01)$ & $-0.03(-0.04,-0.01)$ \\
\hline Non-adjusted & $-0.00(-0.01,0.01)$ & $0.00(-0.00,0.01)$ & $0.01(-0.00,0.01)$ & $-0.03(-0.05,-0.01)$ \\
adjusted & $-0.00(-0.01,0.01)$ & $0.00(-0.00,0.01)$ & 0.010
\end{tabular}

Adjusted variables: age, BMI, menopause's years, diabetic duration, TC, TG, HDL-c, LDL-c, creatinine, UA and eGFR

Q1: <=0.35 ng/ml; Q2: $0.36-0.51 \mathrm{ng} / \mathrm{ml}$; Q3: $0.52-0.73 \mathrm{ng} / \mathrm{ml} ; \mathrm{Q} 4:>=0.74 \mathrm{ng} / \mathrm{ml}$ 
A higher level of HbA1c induces insulin secretion and hypoinsulinemia inhibits the process of bone formation, and PINP was directly associated with insulin resistance, indicating that $\mathrm{HbA1c}$ affects insulin resistance and insulin sensitivity. Reactive oxygen species (ROS) was increased in diabetes by a variety of mechanisms including increased AGEs [27]. Therefore, we hypothesized that a higher level of HbA1c promotes the apoptosis of osteoblast and induces PINP through the production of ROS.

An interesting result in our study is the identification of a segmentation effect between HbA1c and $\beta$-CTX; an inverse relationship between $\mathrm{HbA1c}$ and $\beta$-CTX was found when HbA1c was less than $7.4 \%$, but no association was noted when HbA1c was greater than $7.4 \%$. When quartered the level of $\beta$-CTX, the highest quartile of $\beta$-CTX $(>0.74 \mathrm{ng} / \mathrm{ml})$ showed a significantly negative with HbA1c. Recently, a study involving people with a normal glucose tolerance found that $\beta$-CTX was positively associated with HbA1c [28]. Ogata, Makiko et al. discovered that the CTX-1 level was significantly and negatively correlated with the patients initial $\mathrm{HbA1c}$ level and average HbA1c levels for the previous 6 month [29]. No relationship with $\beta$-CTX was has been noted in recent year [30]. Otherwise, $\beta$-CTX may be a predictor of fracture risk, a higher level of $\beta$-CTX may increase the risk of fracture, the large heterogeneity among studies could be caused by differences in patients' characteristics indicated in a systematic review [20]. Kaori Kitaoka's research may help us to interpret this phenomena, when HbA1c increased from 6.93 to $7.46 \%$, DN progression was significantly accelerated in patients with T2DM, resulting in an increase in $\beta$-CTX exclusion [31]. Besides, a former report discovered the highest quartile of $\beta$-CTX was observably related with a rapid reduction of cortical bone loss [32], and a tight glycemic control (when $\mathrm{HbA} 1 \mathrm{c}<7 \%$ ) was closely related with greater risk of hip fracture in individuals being treated for T2DM were all helpful to explain our results, however additional investigation involving a large clinical prospective survey are required to explore the significance of $\beta$-CTX in the development of T2DM.

Although many confounders was adjusted in our research, there are also some limitations. First, our sample size was not large enough. Second, the cross-sectional survey used in this study limited our ability to identify etiological factors, and since our survey was focused on postmenopausal women suffering from T2DM, the findings herein reported may not suitable for men. Third, we were unable to obtain all of the information regarding all the subjects involved in this study including BMD and risk factors for fracture in order to explore their relationship with $\mathrm{HbA1c}$, bone biochemical markers and BMD. Fourth, detail information regarding the anti-diabetic medications taken by the subjects was not available in this study, since it has been shown that the level of bone biochemical markers was also influenced by different kinds of hypoglycemic drugs.

\section{Conclusions}

Bone formation was inhibited in postmenopausal women with T2DM, but no alteration of the bone resorption marker $\beta$-CTX was observed compared to controls. HbA1c was inversely related to N-MID osteocalcin and PINP. Therefore, a poor glycemic control may aggravate bone loss, increasing the risk of fracture in patients with T2DM.

\section{Abbreviations \\ 25(OH) $D_{3}$ : 25-hydroxyvitamin $D_{3} ; A D A$ : American Diabetes Association; BMD: Bone mineral density; BMI: Body Mass Index; DN: Nephropathy; DPN: Diabetic peripheral neuropathy; DR: Diabetic retinopathy; eGFR: estimated glomerular filtration rate; $\mathrm{HbA1c}$ : Glycosylated hemoglobin A1c; HDL-c: High-density lipoprotein-cholesterol; HPLC: High-performance liquid chromatography; LDL-c: Low-density lipoprotein- cholesterol; OC: Osteocalcin; PINP: Procollagen type 1 amino-terminal pro-peptide; PTH: Parathyroid hormone; SD: Standard deviation; T2DM: Type 2 diabetes mellitus; TC: Total cholesterol; TG: Triglycerides; UA: Uric acid; creatinine; $\beta$ - CTX: $\beta$-crossLaps}

\section{Acknowledgements}

We thank the AJE team for offering the English language editing services, and we are gratefully to Shengqian Xu and Min Zhou for their assistance.

\section{Funding}

This study was supported by the Natural Science Foundation of China (project number: 81571572,81201488 and 30801088).

\section{Availability of data and materials}

The datasets generated analyzed during the current study are not publicly available due to future submission and publication but are available from the corresponding author upon reasonable request.

\section{Authors' contribution}

LW, TL and WW were involved in the study design and writing of the article. $J \mathrm{~L}, \mathrm{XW}, \mathrm{HW}$, and $\mathrm{XL}$ were involved in the data analysis. EX, QC, CY, HL and $Y X$ were involved in data collection. All authors reviewed and approved the final manuscript.

\section{Ethics approval and consent to participate}

All patients provided a written informed consent and ethical approval was given by the Medical Ethics Committee of the First Affiliated Hospital of Anhui Medical University with the following reference number:Quick-PJ2018$11-11$

Consent for publication

Not applicable.

\section{Competing interests}

The authors declare that they have no competing interests.

\section{Publisher's Note}

Springer Nature remains neutral with regard to jurisdictional claims in published maps and institutional affiliations.

Received: 8 October 2018 Accepted: 6 March 2019

Published online: 12 March 2019

References

1. Zakeri Z, Azizi Z, Mehrabifar H, Hashemi M. Evaluation of bone mineral density in premenopausal women with type-2 diabetes mellitus in Zahedan, Southeast Iran. J Pak Med Assoc. 2011;61(5):443-5. 
2. Asokan AG, Jaganathan J, Philip R, Soman RR, Sebastian ST, Pullishery F. Evaluation of bone mineral density among type 2 diabetes mellitus patients in South Karnataka. J Nat Sci Biol Med. 2017;8(1):94-8.

3. Leidig-Bruckner G, Ziegler R. Diabetes mellitus a risk for osteoporosis. Exp Clin Endocrinol Diabetes. 2001;109(Suppl 2):S493-514.

4. De Leeuw I, Abs R. Bone mass and bone density in maturity-type diabetics measured by the 1251 photon-absorption technique. Diabetes. 1977;26(12):1130-5.

5. Oz SG, Guven GS, Kilicarslan A, Calik N, Beyazit Y, Sozen T. Evaluation of bone metabolism and bone mass in patients with type-2 diabetes mellitus. J Natl Med Assoc. 2006;98(10):1598-604

6. Akesson K. Biochemical markers of bone turnover. A review. Acta Orthop Scand. 1995;66(4):376-86.

7. Sellmeyer DE, Civitelli R, Hofbauer LC, Khosla S, Lecka-Czernik B, Schwartz AV. Skeletal metabolism, fracture risk, and fracture outcomes in type 1 and type 2 diabetes. Diabetes. 2016;65(7):1757-66.

8. Purnamasari D, Puspitasari MD, Setiyohadi B, Nugroho P, Isbagio H. Low bone turnover in premenopausal women with type 2 diabetes mellitus as an early process of diabetes-associated bone alterations: a cross-sectional study. BMC Endocr Disord. 2017;17(1):72.

9. Hussein RM. Biochemical relationships between bone turnover markers and blood glucose in patients with type 2 diabetes mellitus. Diabetes Metab Syndr. 2017;11(Suppl 1):S369-72.

10. Razi F, Esmaili M, Esfahani EN, et al. Bone structure and turnover in postmenopausal women with type 2 diabetes mellitus. Menopause. 2016; 23(3):280-5

11. Puar TH, Khoo JJ, Cho LW, et al. Association between glycemic control and hip fracture. J Am Geriatr Soc. 2012;60(8):1493-7.

12. Schwartz AV, Margolis $\mathrm{KL}$, Sellmeyer DE, et al. Intensive glycemic control is not associated with fractures or falls in the ACCORD randomized trial. Diabetes Care. 2012;35(7):1525-31.

13. Furst JR, Bandeira LC, Fan WW, et al. Advanced glycation Endproducts and bone material strength in type 2 diabetes. J Clin Endocrinol Metab. 2016; 101(6):2502-10

14. Okada Y, Okada M. Effects of methanolic extracts from edible plants on endogenous secretory receptor for advanced glycation end products induced by the high glucose incubation in human endothelial cells. J Pharm Bioallied Sci. 2015;7(2):145-50.

15. Dobnig H, Piswanger-Sölkner JC, Roth M, et al. Type 2 diabetes mellitus in nursing home patients: effects on bone turnover, bone mass, and fracture risk. J Clin Endocrinol Metab. 2006;91(9):3355-63.

16. Achemlal L, Tellal S, Rkiouak F, et al. Bone metabolism in male patients with type 2 diabetes. Clin Rheumatol. 2005;24(5):493-6.

17. Rubin MR. Skeletal fragility in diabetes. Ann N Y Acad Sci. 2017;1402(1):18-30.

18. Hamilton EJ, Rakic V, Davis WA, et al. A five-year prospective study of bone mineral density in men and women with diabetes: the Fremantle diabetes study. Acta Diabetol. 2012;49(2):153-8.

19. Terzi R, Dindar S, Terzi H, Demirtaş Ö. Relationships among the metabolic syndrome, bone mineral density, bone turnover markers, and hyperglycemia. Metab Syndr Relat Disord. 2015;13(2):78-83.

20. Starup-Linde J, Vestergaard P. Biochemical bone turnover markers in diabetes mellitus - a systematic review. Bone. 2016;82:69-78.

21. Stage $T B$, Christensen $M H$, Jørgensen NR, et al. Effects of metformin, rosiglitazone and insulin on bone metabolism in patients with type 2 diabetes. Bone. 2018;112:35-41.

22. Yan P, Zhang Z, Wan Q, et al. Association of serum uric acid with bone mineral density and clinical fractures in Chinese type 2 diabetes mellitus patients: a cross-sectional study. Clin Chim Acta. 2018;486:76-85.

23. BAM L, Sundh D, Mellström D. Axelsson KF. Lorentzon M. Association between cortical bone microstructure and statin use in older women. J Clin Endocrinol Metab: Nilsson AG; 2018

24. Botolin S, McCabe LR. Chronic hyperglycemia modulates osteoblast gene expression through osmotic and non-osmotic pathways. J Cell Biochem. 2006;99(2):411-24

25. Lee NK, Sowa $H$, Hinoi $E$, et al. Endocrine regulation of energy metabolism by the skeleton. Cell. 2007;130(3):456-69.

26. Yao Q, Yu C, Zhang X, Zhang K, Guo J, Song L. Wnt/B-catenin signaling in osteoblasts regulates global energy metabolism. Bone. 2017;97:175-83.

27. Hamada $Y$, Fujii H, Fukagawa M. Role of oxidative stress in diabetic bone disorder. Bone. 2009;45(Suppl 1):S35-8.
28. Xuan Y, Sun LH, Liu DM, et al. Positive association between serum levels of bone resorption marker $\mathrm{CTX}$ and $\mathrm{HbA1c}$ in women with normal glucose tolerance. J Clin Endocrinol Metab. 2015;100(1):274-81.

29. Ogata $M$, Ide $R$, Takizawa $M$, et al. Association between basal metabolic function and bone metabolism in postmenopausal women with type 2 diabetes. Nutrition. 2015:31(11-12):1394-401.

30. Starup-Linde J, Lykkeboe S, Gregersen S, et al. Differences in biochemical bone markers by diabetes type and the impact of glucose Bone. 2016;83:149-55.

31. Kitaoka K, Takenouchi A, Tsuboi A, Fukuo K, Kazumi T. Association of Postbreakfast Triglyceride and Visit-to-Visit Annual Variation of fasting plasma glucose with progression of diabetic nephropathy in patients with type 2 diabetes. J Diabetes Res. 2016;2016:4351376.

32. Okuno S, Inaba M, Kitatani K, Ishimura E, Yamakawa T, Nishizawa Y. Serum levels of C-terminal telopeptide of type I collagen: a useful new marker of cortical bone loss in hemodialysis patients. Osteoporos Int. 2005;16(5):501-9.

\section{Ready to submit your research? Choose BMC and benefit from:}

- fast, convenient online submission

- thorough peer review by experienced researchers in your field

- rapid publication on acceptance

- support for research data, including large and complex data types

- gold Open Access which fosters wider collaboration and increased citations

- maximum visibility for your research: over $100 \mathrm{M}$ website views per year

At BMC, research is always in progress.

Learn more biomedcentral.com/submissions 